\section{PRIMARY PNEUMONIA}

\section{A TWO-YEAR SURVEY OF CASES TREATED NON-SPECIFICALLY \\ BY}

\section{H. JOULES, M.D., M.R.C.P.}

PHYSICIAN, SELLY OAK HOSPITAL, BIRMINGHAM

The profession seems to be awaking belatedly to the immense problem of pneumonia. This is due to the advent of specific serum therapy, and also, I think, to some realization of the great number of cases treated in municipal hospitals. Thus it is pertinent to inquire into what may be the natural history of this condition at the present time in cases where no specific therapy is used. The ensuing series has been dealt with in the adult medical wards of Selly Oak Hospital during the period March, 1930, to March, 1932.

\section{Diagnosis and Treatment}

Diagnosis has rested upon the characteristic history of onset, sputum, and the definite establishment of physical signs of consolidation. No case has been included in which these physical signs have been absent. It appears to me that much of the success claimed by pioneers in various fields of therapy is obtained in those cases which naturally abort within thirty-six hours, without ever developing definite signs of the established disease. During an epidemic of pneumonia the hospital wards always contain numerous examples of this condition-dealt with as adequately by calomel as by specific therapy. Some criterion of diagnosis must be established before dogmatism can take place on definite curative results within the first forty-eight hours of so-called pneumonia. It has seemed to me that any strict clinical distinction between bronchopneumonia and the lobar type is not possible, and, although many of the ensuing cases have been only lobar in distribution and character, post-mortem examination has demonstrated in a few instances the coexistence of both types in different lobes. I therefore decided to investigate primary pneumonia and not to attempt any more strict classification-if, indeed, one is always possible. The population from which the hospital draws its material is similar to that of most voluntary hospitals in any large town, except that in a municipal hospital we have to deal rather more extensively with the very poor. It will be seen, therefore, that with the prevailing economic depression and unemployment, these figures relate to the prognosis of pneumonia among those in whom it should be and is most unfavourable. The frequency, too, is much greater in the congested areas which the hospital serves, and I feel sure that much of the incidence, death rate, and crippling effect of pneumonia is directly related to bad housing, overcrowding, and straitened economic circumstances.

The treatment has followed no set plan, but the basis of it has been:

1. Adequate fluids throughout, with continuous rectal salines in those cases where insufficient fluid has been taken by mouth, at least eight pints daily being given. Glucose in large amounts' to all cases.

2. Complete rest in the position most favoured by the patient.

3. The administration of sufficient hynotic, often morphine, to ensure sound sleep, particularly in the early days.

4. Continuous intranasal oxygen in any severe infection.

5. An effective clearing of the lower bowel in all cases.

6. The administration of alcohol to cases with delirium - particularly where the history suggested a partiality to this beverage, as was not infrequent-and to those who, at or near the crisis, showed a failing appetite or loss of interest in life. Other stimulants were kept for dealing with emergencies as they arose, and digitalis was only administered to cases where auricular fibrillation was found.

7. Pain was dealt with by local application, and the time-honoured linseed and mustard poultice was found of great service in severe pleural pain.

8. Subsequent to the fall in temperature an adequate reinflation of the affected lung was attempted by means of breathing exercises.

\section{INCIDENCE AND MORTALITY, ETC.}

The age period was 10 to 70 years, and the total number of cases under review during the two years was 496 . Complete bacteriological investigation and typing of the pneumococcus was not undertaken, owing to pressure of work. The sex incidence, as shown in Table $I$, is in accordance with accepted teaching-namely, 68 per cent. males and 32 per cent. females-while 70 per cent. of the cases were encountered in the months October to April inclusive, which also agrees with common findings.

\begin{tabular}{l|c|c|c|c|c|c|c|c|c}
\multicolumn{9}{c|}{ TABLE I.-Incidence } \\
\hline & & \multicolumn{5}{c|}{ Decade } & Total & Percentage \\
\cline { 2 - 6 } & $10-20$ & $20-30$ & $30-40$ & $40-50$ & $50-60$ & 60 and over & & \\
\hline Males & $\ldots$ & 49 & 68 & 74 & 62 & 57 & 28 & 338 & 68 \\
Females & $\ldots$ & 28 & 18 & 36 & 31 & 19 & 26 & 158 & 32 \\
\hline
\end{tabular}

It was noteworthy throughout that practically all patients who recovered had a higher pulse rate during the thirty-six hours subsequent to admission than they had at any other day of their stay. This was taken as indicating that the movement to hospital was temporarily imposing more strain than the height of the infection itself. It is also important to note the mortality rate increasing as the length of duration of symptoms prior to removal to hospital increases. This is seen in Table II.

\begin{tabular}{l} 
TABL.E II.-Mortality and Day of Admission to Hospital \\
\hline \\
\cline { 2 - 6 }
\end{tabular}

Deaths numbered 127-the gross mortality during the whole period being 25.6 per cent.-but of this total thirtyone were moribund on admission and died within thirtysix hours. If these are excluded, I find a mortality rate of 20.6 per cent. It was noticed that this varied from one influx of cases to another-during January and February, 1931, eighty-three patients were admitted, with a mortality percentage of 35 .

In considering other points relating to mortality, the gross figures are used throughout.

The age factor appeared to me to exert one of the maximal effects in bad prognosis. These facts are well brought out in Table III.

\begin{tabular}{|c|c|c|c|c|c|c|c|}
\hline & & \multicolumn{6}{|c|}{ Decade } \\
\hline & & $10-20$ & $|20-30|$ & $30-40$ & $40-50 \mid$ & $50-60$ & 60 and over \\
\hline $\begin{array}{l}\text { Total deaths per } \\
\text { decade }\end{array}$ & $\left\{\begin{array}{l}\text { Male } \ldots \\
\text { Fema:e }\end{array}\right.$ & $\begin{array}{c}1 \\
\text { Nil }\end{array}$ & $\begin{array}{l}9 \\
3\end{array}$ & $\begin{array}{r}16 \\
5\end{array}$ & $\begin{array}{l}25 \\
12\end{array}$ & $\begin{array}{r}23 \\
9\end{array}$ & $\begin{array}{r}16 \\
8\end{array}$ \\
\hline $\begin{array}{l}\text { Percentage of deaths } \\
\text { per decade }\end{array}$ & $\begin{array}{l}\text { Male ... } \\
\text { Female }\end{array}$ & $\begin{array}{l}2.0 \\
\text { Nil }\end{array}$ & $\begin{array}{l}13.2 \\
16.7\end{array}$ & $\begin{array}{l}21.6 \\
14.0\end{array}$ & $\begin{array}{l}41.0 \\
39.0\end{array}$ & $\begin{array}{l}40.0 \\
47.0\end{array}$ & $\begin{array}{l}57.0 \\
31.0\end{array}$ \\
\hline
\end{tabular}


It is evident from the preceding tables that the gross mortality for cases under 40 years is $\mathbf{1 2 . 5}$ per cent., while over that age the figure is 41.7 per cent. ; it is thus among the older group that benefits from specific remedies should be sought, as any small series having a low age incidence will naturally tend to show an excellent prognosis.

In view of the shortening of duration of temperature which is said to follow specific remedies, it was considered beneficial to inquire the period of duration in this series. The results are shown in the table.

TABI.E IV.-Duration of Temperature in Days

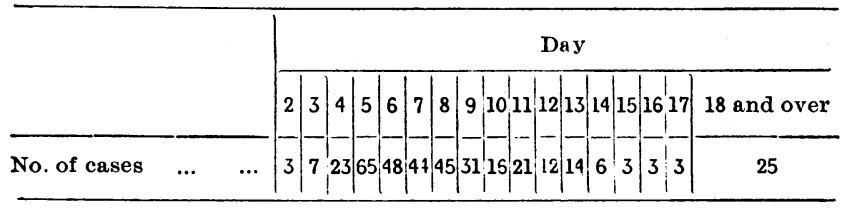

From this it will be seen that 70 per cent. of cases reach a normal temperature before the tenth day, with a maximal incidence on the fifth day. The incidence of deaths was found to correspond fairly accurately with the day of the fall in temperature as set out above.

In severe cases with much bronchitis it is sometimes difficult to assess clinically the extent of lobar involvement; but there was found a close relation between the lobar extent and the prospect of a favourable prognosis. In those cases living the clinical involvement was: one lobe, 241 cases ; two lobes, 116 cases ; three lobes, 25 cases. Post-mortem examination was undertaken in 59 cases, when the numbers were: one lobe, 10 ; two lobes, 18 ; three or more lobes, 31 . Despite some recent assertions it is thus seen that there is a direct correspondence between the extent of lesion and the mortality rate as shown in Table $\mathrm{V}$.

\begin{tabular}{|c|c|c|c|}
\hline & One Lobe & Two Lobes & $\begin{array}{c}\text { Three or More } \\
\text { Lobes }\end{array}$ \\
\hline Cases living $\ldots$ & $241=60.5 \%$ & $116=30.3 \%$ & $25=7.0 \%$ \\
\hline Post mortem ... & $10=16.9 \%$ & $18=30.0 \%$ & $31=52.0 \%$ \\
\hline
\end{tabular}

\section{Complications}

The outstanding complications met with in the series as detected were:

$$
\begin{aligned}
& \begin{array}{lccccccc}
\text { Empyema } & \ldots & \ldots & \ldots & \ldots & \ldots & \ldots & 19(14 \mathrm{~L}, 5 \mathrm{D}) \\
\text { Sterile effusions } & \ldots & \ldots & \ldots & \ldots & \ldots & \ldots & 5(\mathrm{~L})
\end{array} \\
& \begin{array}{llllll}
\text { Non-suppurative arthritis } & \ldots & \ldots & \ldots & \ldots & 5(\mathrm{~L}) \\
& \ldots & \ldots & \ldots & \mathbf{6}(\mathrm{L})
\end{array}
\end{aligned}
$$

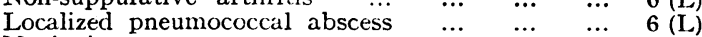

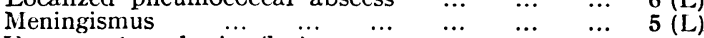

$$
\begin{aligned}
& \begin{array}{lllllll}
\text { Venous thrombosis (leg) } & \ldots & \ldots & \ldots & \ldots & 5(\mathrm{~L}) \\
\end{array} \\
& \begin{array}{lllllll}
\text { Venous thrombosis } & & \ldots & & & & \\
\text { Parotid abscess } \ldots & \ldots & \ldots & \ldots & \ldots & \ldots & 5(\mathrm{~L}) \\
\text { Erythema multiforme } & \ldots & \ldots & \ldots & \ldots & \ldots & 2(1 \mathrm{~L}, 1 \mathrm{D}) \\
\end{array} \\
& \begin{array}{lllllll}
\text { Erythema multiforme } & \ldots & \ldots & \ldots & \ldots & \ldots & 2(1 \mathrm{~L}, 1 \mathrm{D}) \\
\text { Pyopneumothorax... } & \ldots & \ldots & \ldots & \ldots & \ldots & 2(1 \mathrm{~L}, 1 \mathrm{D})
\end{array}
\end{aligned}
$$

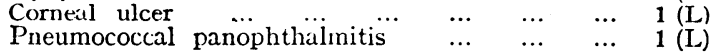

$$
\begin{aligned}
& \mathrm{L}=\text { Survived. } \quad \mathrm{D}=\text { Died. }
\end{aligned}
$$

The most outstanding feature here is that in all six cases where a multiple non-suppurative arthritis was found a fatal termination ensued. The occurrence of sterile effusions, the cytology of which closely resembled that found in many cases of idiopathic effusions which are labelled tuberculous, should give rise to speculation as to the number of these cases which are the result of a pneumococcal or streptococcal pulmonary infection, where the lung lesion is of limited extent. The 100 per cent. recovery rate in cases where metastatic pneumococcal abscesses were found prompted the thought that in severe pneumococcal infections treatment by means of fixation abscesses, either from lung-puncture fluid or other means, might be worthy of trial. The two pyo- pneumothoraxes were obviously the result of rupture of a superficial lung abscess: culture of the foul fluid in both revealed large numbers of anaerobic organisms. Despite this, wide drainage sufficed to bring about a favourable issue in one case. The instance of pneumococcal panophthalmitis must be one of considerable rarity. The condition, associated with a left pneumococcal empyema, appeared to commence as an iritis, but within twenty-four hours there was cloudiness in the anterior and posterior chambers, while subsequent evisceration of the eye revealed a semi-purulent aqueous and vitreous humour yielding a pure pneumococcal culture. Simultaneous drainage of the empyema was followed by an uninterrupted recovery.

\section{Post-MORTEM Findings}

Fifty-nine cases were subjected to necropsy. The extent of the pulmonary lesion has been set out above. The gross extent of this is noteworthy, and few cases failed to reveal either some serious complication indicative of both direct and blood-spread infection, or the coexistence of some other disease. Pericarditis was found in ten instances, and in each it was associated with disease of the left lung. This would lend support to the fact that this lesion is the result of a direct spread of infection comparable to pleurisy and empyema. It was absent in two cases in which pneumococcal endocarditis was demonstrated. I have found the clinical diagnosis of pericarditis extremely baffling in many severe cases owing to the innumerable added sounds in the chest. The not infrequent existence of a pleuro-pericardial friction, usually on the left side, has also added to the difficulty. To such an extent has this been true that in those cases recovering I have been inclined to regard all friction sounds near the left border of the heart, and rhythmical in quality, as having a pleuro-pericardial origin. Consequently, reliable statistics of survival rate in pericarditis are difficult to obtain.

The frequency of lung abscess was a feature in the series, eleven cases being seen, and it was noteworthy that the major incidence of this coincided with the severe epidemic noted above. In only two cases was previous evidence suggestive of this condition; the remainder were " closed" at the time of death. This frequency rate would suggest that superficial abscesses do at times result in empyema formation, as clinical lung abscesses are rare, and rupture into the pleura may be one method of drainage. Ten empyemas in all were seen-again in this complication the percentage was much higher than in convalescent cases. Four of these were associated with pneumococcal peritonitis.

\begin{tabular}{|c|c|c|c|c|}
\hline & $\begin{array}{c}\text { Lung } \\
\text { Abscess }\end{array}$ & Empyema & $\begin{array}{c}\text { Pneumoenceal } \\
\text { Peritonitis }\end{array}$ & $\begin{array}{l}\text { Pnemmocneceal } \\
\text { Endocarditis }\end{array}$ \\
\hline No. of cases $\quad \ldots \quad \ldots$ & 11 & 10 & 4 & 2 \\
\hline Percentage of total ... & 18.6 & 16.9 & 6.7 & 3.5 \\
\hline
\end{tabular}

Table VI summarizes the important post-mortem lesions.

TABLE VI.-Chief Complications Discovered Post Mortem

\section{The Problem of Hospitalization}

Pneumonia, as is well appreciated by all who are in intimate contact with the condition, is a notoriously difficult disease on which to dogmatize. Its too frequently fulminating progress, or its equally frequent dramatic subsidence, will at times confound the most expert prognosis. It may well be that blood culture will be of immense value in this direction. The famed stand-by of blood-pressure-pulse-rate ratio has not appeared to me to warrant the value so often ascribed to it. Despite all difficulties, however, certain facts do force themselves on one's notice in considering the subject. 
A survey of the mortality rate for the city of Birmingham indicates an incidence rate three times as great. in the overcrowded, badly housed population in the inier ring of the city (where economic factors play an important part) as that in the outer ring, where housing, ventilation, and social factors do not devitalize the inhabitants. Sunless courts and alleys are still too frequently the causes of an overcrowded hospital, for had cases of pneumonia under 10 years of age been included in this survey approximately one thousand primary infections would have been seen, and those in two years!

Emphasis has been laid on the tremendous extent of infection of those dying, and when this is considered in conjunction with the figures showing the day of disease on which patients were admitted to hospital it will be apparent that in the present circumstances, whatever mode of therapy is used, one must expect an irreducible mortality of at least 15 per cent. or over. I feel that where home conditions are good and adequate help is available the movement of patients is quite correctly deprecated: where these conditions do not obtain I feel that every inducement should be employed to persuade patients and relatives to permit removal at the earliest possible juncture. Too often I see an almost hopeless sufferer admitted on the fifth day, accompanied by one or more relatives whose whole vitality has been sapped in a vain endeavour to see the illness through in most unfavourable circumstances. The nursing of pneumonia is one of the most exacting tasks any unaided household can undertake, and it may be that if this fact were forcibly placed before those concerned consent for hospitalization in suitable cases would be obtained more readily. It is impossible to visualize any serum so potent that it would prove capable of re-establishing a circulation which is failing from peripheral paralysis, as is the case with many of our patients on admission. Again, where more than half the lung area is consolidated, is it likely that sterilization of the blood in the later days is going to be of sufficient service to allow recovery to take place? A large percentage of elderly patients will always succumb to the disease, but it is in the third, fourth, and fifth decades that we need cvery possible assistance in preventing the death of the mainstay of large families.

\section{Summary and Conclusions}

1. 497 cases of primary pneumonia with an incidence of ten years and upwards are reviewed.

2. A criterion of diagnosis in early stages of the disease is needed.

3. No specific therapy was given, and the gross mortality rate was 25.6 per cent. Excluding those moribund on admission the mortality rate was 20.6 per cent.

4. Prognosis was more dependent on age than on any other factor. Mortality for cases under 40 years was 12.5 per cent., for those over 40 years 41.7 per cent.

5. Pulmonary abscess is a fairly common post-mortem finding.

6. A plea is made for cases of pneumonia to be sent to hospital as early as possible in the disease.

I am grateful to several of my colleagues for the use of their notes in preparing this article.

\section{ON THE TREATMENT OF NEW GROWTHS BY FLUORESCEIN AND X RAYS* \\ BY}

\author{
HECTOR A. COLWELL, M.B., Ph.D., M.R.C.P.
}

The cases which form the subject of the present note were treated by the combined $x$-ray and fluorescein method. It had been represented to me that the treatment was harmless and that good clinical results had followed its use. It had also been suggested that such benefit as was recorded might be due to some secondary radiation produced by the action of $x$ rays upon fluorescein. At the outset it may be said that such an action of penetrating radiations of the $x$ - and $\gamma$-ray type was regarded as in the highest degree improbable when the chemical composition of the drug employed-sodium fluorescein-was taken into consideration. In all cases sodium fluorescein was administered by the mouth, and in some cases a 5 per cent. solution was employed locally, but only at the time of $x$-ray treatment. For oral administration about 1 gram was given, divided into two cachets, four hours before $x$-ray treatment. The skin and conjunctivae were well coloured by the dye, which was manifest also in the sweat, urine, and exudates from ulcerated surfaces, when these were present. The local application of a $\mathbf{5}$ per cent. solution of sodium fluorescein was confined to those cases in which ulceration was present.

The obvious difficulty in estimating the value of such a method of treatment is that of obtaining suitable controls. Growths respond differently to radiations, and one and the same growth may show a tendency either to rapid increase or to temporarily diminished activity spontaneously. Nevertheless, as will be seen, an attempt at a very rough control was made.

* The expenses of this work were defrayed by a grant from the Medical Research Council.
Forty-five cases were treated. In the great majority of them it was impossible to state that the administration of fluorescein had influenced the action of the radiation in the slightest degree. Some cases of ulcerated mammary carcinoma did, however, appear to respond better to $x$-ray treatment when fluorescein was used at the same time. Six cases of carcinoma of the rectum in which there was a mass of growth protruding from the anus did not derive the least benefit. The total number of recurrent breast cases treated was thirty: of these, fifteen showed local ulceration; the remaining fifteen showed enlarged supraclavicular and axillary glands with or without subcutaneous carcinomatous nodules. Of the fifteen cases of ulcerated mammary cancer five had been receiving ordinary routine $x$-ray therapy before fluorescein treatment was started, and it was these five cases which served as a very rough control. In three of them it certainly appeared as though the local condition improved more under the fluorescein treatment; in the remaining two it was apparently without effect-either good or bad. Of the remaining ten cases of ulcerated breast cancer in the treatment of which fluorescein was used from the first, perhaps six seemed to make what seemed to be unusually good progress; the remaining four showed no special features.

To this matter we shall return shortly. As already said, no special effect was noted with the six rectal cases and with the fifteen non-ulcerated breast cases; while the same was true of two cases of neoplasm of the lung, three of non-ulcerated bone sarcoma, and four of lymphadenoma. The sum-total of the therapeutic experiment was, then, that nine cases of ulcerated recurrent breast carcinoma seemed to have been benefited to some extent by the use of fluorescein.

We may now turn to the consideration of certain laboratory experiments which were carried out by Dr. Creed and myself upon mice, tadpoles, and toad ova. In the case of the mice, these animals were fed upon the ordinary laboratory food to which had been added a 5 per cent. solution of sodium fluorescein. They took 